\title{
Descrição de um surto de lepidopterismo (dermatite associada ao contato com mariposas) entre marinheiros, ocorrido em Salvador, Estado da Bahia
}

\author{
Description of an outbreak of lepidopterism (dermatitis associated \\ with contact with moths) among sailors in Salvador, State of Bahia
}

\author{
Shirlei Cristina Moreira ${ }^{1}$, Jean Carla de Lima ${ }^{2}$, Lucineide Silva ${ }^{2}$ e Vidal Haddad Junior ${ }^{3}$
}

\begin{abstract}
RESUMO
A ocorrência uma dermatite pápulo-pruriginosa em toda a tripulação de um navio comercial filipino em Salvador, BA, foi associada ao contato com mariposas do gênero Hylesia. Esta enfermidade insólita é causada por cerdas corporais das mariposas (flechettes). O relato dos casos serve como alerta para possiveis situações semelhantes.
\end{abstract}

Palavras-chaves: Doenças ocupacionais. Lepidópteros. Hylesia.

\section{ABSTRACT}

An occurrence of pruritic papular dermatitis among the whole crew of a Filipino commercial ship in Salvador, State of Babia, was associated with contact with Hylesia moths. This unusual type of dermatitis is caused by the bristles (flechettes) on the moths' bodies. Reporting on such cases serves to warn about possible similar situations.

Key-words: Occupational diseases. Lepidoptera. Hylesia.

A palavra lepidóptero, do grego lepis, idos e ptera significa asa escamosa. Os acidentes desencadeados pelo contato com as formas adultas aladas de mariposas não são comuns, ao contrário dos acidentes pelas formas larvárias ou lagartas ${ }^{7}$. 0 quadro é denominado lepidopterismo e é provocado na maioria dos casos por mariposas do gênero Hylesia, da família Hemileucidae. Estas dermatites não são comuns e a literatura sobre o tema é escassa $^{123456789101112}$. Existem relatos de acidentes provocados pelas cerdas existentes no abdome de fêmeas de Hylesia em vários países das Américas, inclusive no Brasil' 23456789101112. As mariposas provocam surtos epidêmicos em áreas rurais nos meses quentes e chuvosos, quando circulam e se debatem contra focos de luz.

Existe controvérsia a respeito do fato das espículas abdominais conterem toxinas ${ }^{4}$. A simples penetração das cerdas é capaz de provocar reações inflamatórias intensas, manifestadas por pápulas e prurido ${ }^{2578}$. Estas cerdas (flechettes ${ }^{110}$ ) apresentam farpas microscópicas e se destacam com facilidade das mariposas, flutuando em nuvens nos ambientes onde estão presentes, geralmente acampamentos ou casa de veraneio, podendo inclusive se depositar nas roupas. 0 exame histopatológico costuma evidenciar inflamação intensa e pode mostrar a presença das cerdas.

\section{RELATO DOS CASOS}

No dia 23 de maio de 2006, após notificação da Agência Nacional de Vigilância Sanitária (ANVISA) sobre a ocorrência de acometimento de reação cutânea pruriginosa em todos os 22 tripulantes de uma embarcação comercial filipina, uma equipe da vigilância epidemiológica do Estado da Bahia realizou investigação de campo para a identificação da etiologia do surto. O navio havia saído da Venezuela através do rio Orinoco até Trinidad e Tobago, tendo iniciado sua viagem no dia 13 de maio de 2006 até Salvador, sem escalas. As atividades desenvolvidas na embarcação compreendiam equipes com atuação no exterior da mesma e outras com atividades internas na área coberta. Quando em trabalho externo, os tripulantes utilizam roupas e botas (EPI'S - equipamentos de proteção individuais) que deixam expostas apenas a face, pescoço e antebraços.

\footnotetext{
1. Fundação Nacional de Saúde, Salvador, BA. 2. Ministério da Saúde, Salvador, BA. 3. Universidade Estadual Paulista, Botucatu, SP. Endereço para correspondência: Dr. Vidal Haddad Junior. Caixa Postal 557, 18618-000 Botucatu, SP.

Telefax: $55143882-4922$

e-mail: haddadjr@fmb.unesp.br

Recebido para publicação em: 09/04/2007

Aceito em: 23/08/2007
} 
Os primeiros casos da dermatite tiveram início súbito e ocorreram imediatamente após exposição dos tripulantes a uma grande quantidade de mariposas em migração, nas localidades de Boca Grande, na Venezuela, e em Trinidad e Tobago. Estas mariposas foram coletadas no navio e identificadas como pertencentes ao gênero Hylesia pelo pesquisador Roberto Henrique Pinto Moraes no Laboratório de Parasitologia do Instituto Butantan, São Paulo (Figura 1). Logo se seguiram outros casos, associados aos tripulantes que exerciam atividades externas na embarcação.

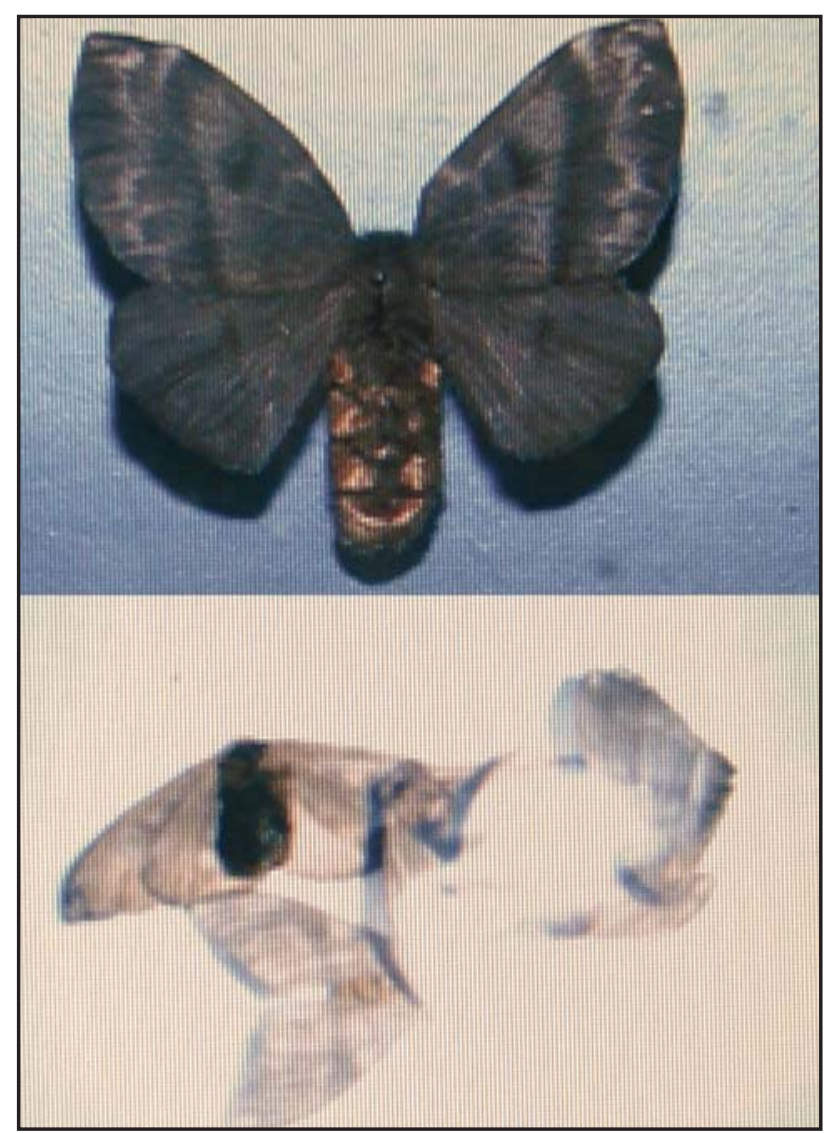

Figura 1 - Fêmea de Hylesia sp. Fotografia: Roberto Henrique Pinto Moraes, Instituto Butantan. Mariposas coletadas no convés do navio e identificadas como pertencentes à família Hemileucidae, gênero Hylesia (acima).

Em fase posterior, toda a tripulação (22 indivíduos) apresentou lesões eritemato-pápulo-pruriginosas acometendo áreas expostas do tegumento (Figuras 2 e 3). Dois pacientes foram submetidos à biópsia cutânea, para exame histopatológico das lesões. As lesões evoluíram para pápulas escoriadas que persistiram por 9 a 14 dias. 0 tratamento foi realizado com dexclorfeniramina $6 \mathrm{mg}$ de 8/8horas nos casos graves e $6 \mathrm{mg}$ à noite nos casos moderados, além de creme de dexametasona 2 vezes ao dia. Como medida complementar, recomendou-se a realização de limpeza das instalações, móveis e utensílios, incluindo paredes, com pano umedecido em água. Para tal atividade o responsável deveria usar os equipamentos de proteção individual, evitando áreas de pele expostas. Os pacientes foram orientados ainda a lavar todo o vestuário, roupas de cama, banho e toalhas de mesa, evitando agitá-las antes da lavagem. A resposta terapêutica foi boa, mas

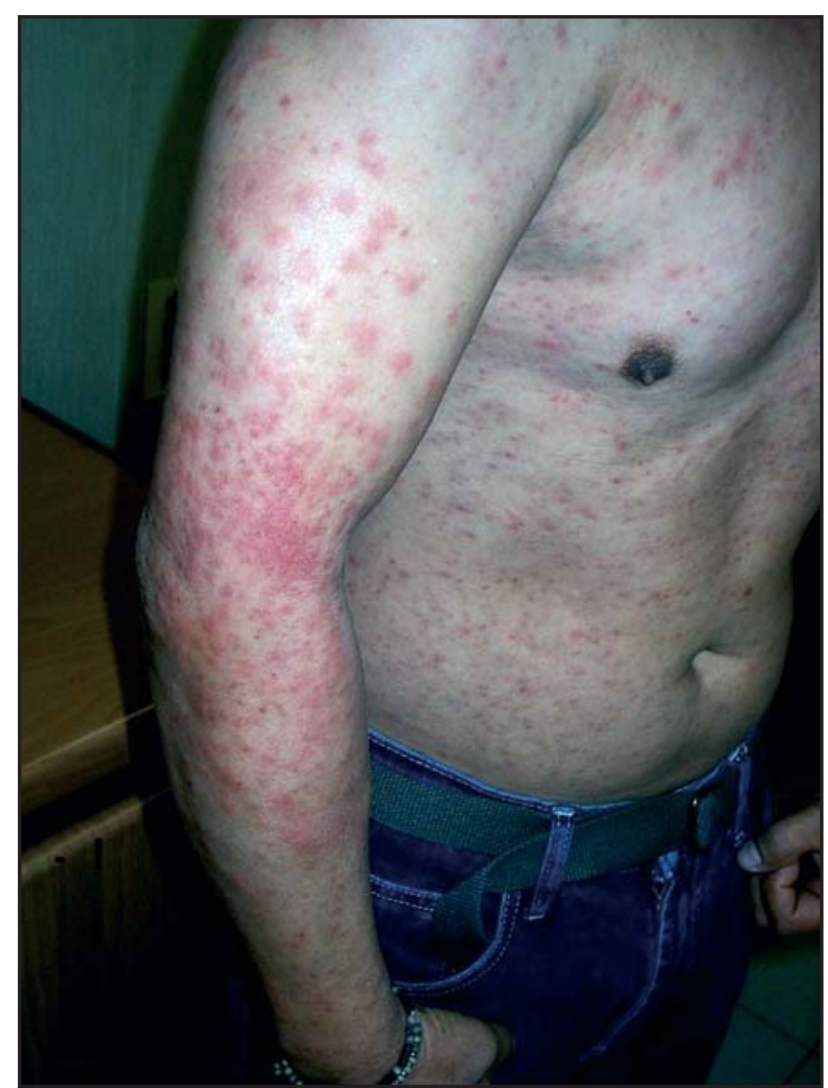

Figura 2 - Paciente apresentando erupção pápulo-pruriginosa com crosta central mais intensa nas áreas expostas. Existe inflamação importante.

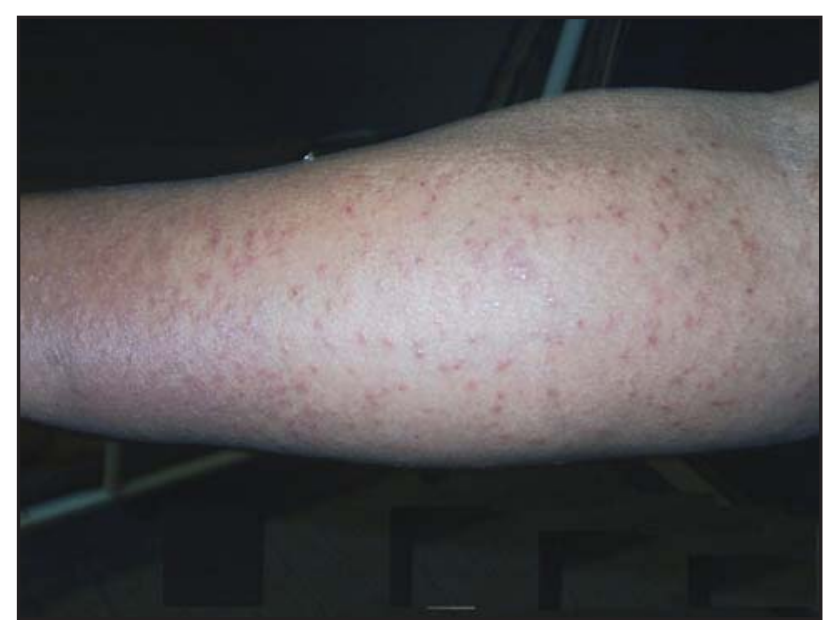

Figura 3 - Detalbe das pápulas eritematosas no antebraço de um paciente.

a embarcação foi orientada a permanecer no Porto de Salvador até melhora clínica da tripulação, quando então foi liberada para seguir viagem. A embarcação foi novamente detida, 30 dias depois, ao chegar à China para inspeção e liberada após apresentação de relatório elaborado pelo dermatologista em Salvador.

\section{DISCUSSÃo}

Os acidentes por mariposas do gênero Hylesia apresentam várias descrições anteriores ${ }^{123456789101112}$. Neste surto, é curioso 
ressaltar que o isolamento dos pacientes na embarcação aumentou a exposição às cerdas e todos os tripulantes apresentaram a dermatite. A presença das mariposas foi fundamental para o diagnóstico uma vez que dois exames histopatológicos não foram conclusivos, não mostrando as cerdas (flechettes) presentes na pele e sim vesículas intraepidérmicas e infiltração mononuclear permeada de eosinófilos, quadro sugestivo da dermatite. No intuito de registrar a enfermidade e alertar os viajantes, sugerimos o acréscimo do lepidopterismo à relação de doenças do viajante (travellers' health) segundo classificação da Organização Mundial de Saúde.

\section{AGRADECIMENTOS}

Aos Doutores Miriam Gonçalves, Marcos Bomfim e Eronilson Costa, da Agência Nacional de Vigilância Sanitária, ao Doutor Juarez Pereira Dias, da Secretaria de Saúde do Estado - SESAB), às Dras. Tereza Badaró Gonzalez, Tânia Coutinho e Lúcia Alves, do Hospital Dom Rodrigo Menezes, ao Dr. Roberto Henrique Pinto Moraes, do Laboratório de Parasitologia do Instituto Butantan, SP e Dr ${ }^{\mathrm{a}}$ Carla Leite, do Histolab, pelo auxílio em diversas fases do trabalho.

\section{REFERÊNCIAS}

1. Boyé R. La Papillonite Guyanese. Bulletin de la Societé de Pathologie Exotique 25: 1099-1107, 1932
2. Cardoso JLC, Borges Filho TS, Carneiro ECG. Surto de dermatite por Hylesia paulex no litoral do Estado de São Paulo, Bertioga, verão 1990. Memórias do Instituto Butantan 52: 82, 1990.

3. Dinehart SM, Archer ME, Wolf Jr JE. Caripito itch: dermatitis from contact with Hylesia moths. Journal of the American Academy of Dermatology 13: 743-747, 1985.

4. Dinehart SM, Jorizzo JL, Soter NA. Evidence for histamine in the urticating hairs of Hylesia moth. Journal of Investigative Dermatology 88: 691-693, 1987.

5. Glasser CM, Cardoso JLC, Carréri-Bruno GC. Surtos epidêmicos de dermatite causada por mariposas do gênero Hylesia (Lepidoptera: Hemilucidae) no Estado de São Paulo, Brasil. Revista de Saúde Pública 27: 217-220, 1993.

6. Gusmão HH, Foratini OP, Rotberg A. Dermatite provocada por lepidóptero do gênero Hylesia. Revista do Instituto de Medicina Tropical de São Paulo 3: 114-120, 1961.

7. Cardoso AEC, Haddad Jr V. Acidentes por lepidópteros (larvas e adultos de mariposas): estudo de aspectos epidemiológicos, clínicos e terapêuticos. Anais Brasileiros de Dermatologia 80: 571-578, 2005.

8. Haddad Jr V, Cardoso JLC. Erucismo e Lepidopterismo. In: Cardoso JLC, Wen FH, França FOS, Malaque CMS, Haddad Jr V (eds) Animais peçonhentos no Brasil: biologia, clínica e terapêutica dos acidentes, Editora Sarvier, São Paulo, p. $220-223,2003$.

9. Hill WR, Rubenstein AD, Kovacs Jr J. Dermatitis resulting from contact with moths (genus Hylesia): report of cases. Journal of the American Medical Association 138: 737-740, 1948.

10. Leger M, Mouzels P. Dermatose prurigineuse determinée par des papillons Sartunides du genre Hylesia. Bulletin de la Societe de Pathologie Exotique 11: $104-107,1918$

11. Tyzzer FF. The pathology of the brown tail moth dermatitis. Journal of Medical Research 11:43, 1907.

12. Zaias N, Ioannides G, Taplin D. Dermatitis from contact with moths (genus Hylesia). Journal of the American Medical Association 207:525-527, 1969. 